\title{
Edmund Becher Wilson’s Early Contributions to the Chromosome Theory of Heredity: A Case Study of Instrumentalism in Science
}

\author{
Lilian Al-Chueyr Pereira Martins \\ University of São Paulo
}

\begin{abstract}
The chromosome theory of inheritance was established during the three first decades of the 20th century. During the early stage of its substantiating, there were lots of puzzles and little evidence that could validate it. The cytological processes were obscure and several scientists maintained serious doubts concerning the existence of a connection between Mendel's principles and the behaviour of chromosomes during cell division. It was vital to associate an external, observable characteristic of the organism to a specific chromosome, and this was achieved when sex was connected to special chromosomes. At that time, however, some important scholars refused to accept or delayed acceptance of the conception that the hereditary factors (later called genes) were physical entities located along the chromosomes. Such was the case of Thomas Morgan (1866-1945) and William Bateson (1861-1926). Their attitudes could be explained by considering the doubtful ground of the hypothesis at that time. It is more difficult, however, to understand the attitude of Edmund Beecher Wilson (1856-1939). Being an expert in cytology he was acquainted with all the difficulties concerning the chromosome hypothesis. Nonetheless, from 1905 onward, he attributed little weight to the problems and dedicated a notable effort to obtaining evidence that could have grounded it. This paper analyses Wilson's attitude focusing on his studies from 1900 to 1915 and the scientific context of this period. This study led to the conclusion that Wilson's attitude could be explained in methodological terms by the adoption of an instrumentalist attitude, while Bateson and Morgan adopted a realistic perspective.
\end{abstract}

Keywords: history of genetics, philosophy of biology, chromosome hypothesis/theory, Wilson, Edmund Beecher, instrumentalism

\section{Introduction}

The chromosome theory of inheritance was established during the first three decades of the 20th century. It assumed that the factors (the bearers of hereditary characteristics) were material entities located along the nuclear chromosomes and attempted to establish a parallel between the behaviour of chromosomes during cell division (cytological or microscopic level) and the results of experimental crossings (macroscopic level).

The first cytological hints favourable to this idea were presented by Theodor Boveri (1862-1915) and

Lilian Al-Chueyr Pereira Martins, Prof., Dr., Department of Biology, University of São Paulo, Campus Ribeirão Preto, Brazil; main research fields: History and Philosophy of Biology mainly focusing on Classical Genetics and Evolution.

Acknowledgements: The author is grateful to the Brazilian National Council of Scientific and Technological Development (CNPq) and to the São Paulo State Research Foundation (FAPESP) for supporting this research. Besides that, she is also grateful to Prof. Dr. Anna Carolina Regner for her comments and criticisms that contributed to the improvement of this paper. 
Walter Sutton (1877-1916), in 1902 and 1903. Their work seemed to show that the chromosomes preserve their individuality during all the phases of cell division (Sutton), and that different chromosomes play different roles in the development of the organism (Boveri). However, they did not obtain any evidence of the association of specific chromosomes to any observable characteristic of the organisms they had studied.

During the early stage of the substantiation of the chromosome theory, there were lots of puzzles and little evidence that could validate it. The cytological processes were obscure and several scientists maintained serious doubts concerning the existence of a connection between Mendel's principles and the behaviour of chromosomes during cell division. The individuality and constancy of chromosomes were still doubtful. Without assuming the individuality and constancy of the chromosomes, it was difficult to explain the constancy of Mendel's factors and the purity of the gametes. It was vital to associate an external, observable characteristic of the organism to a specific chromosome. This was achieved when sex was connected to special chromosomes. Historians of science, such as Garland Allen and Ernst Mayr, considered that important contributions to the problem of sex determination came in 1905 with the independent work of Edmund Beecher Wilson and Nettie Maria Stevens (Allen 1978, 129; Mayr 1982, 751).

At that time, however, some important scholars refused to accept or delayed acceptance of the conception that the hereditary factors (later called genes) were physical entities located along the chromosomes. Such was the case of Thomas Morgan (1866-1945) and William Bateson (1861-1926). During the first decade of the 20th century, both researchers were sceptical concerning the theory and did not dedicate any effort to the study of chromosomes. It is easy to understand their attitudes: We expect that someone who does not believe that a theory is true will not dedicate much effort to the investigation of that theory-except if he/she intends to refute it (Martins 2002).

It is also easy to understand their attitudes during the second decade of the 20th century taking into account their beliefs. Around 1910, Morgan began to accept the chromosome theory of heredity, and from that time onwards, he devoted most of his time to the substantiation of that conception, without giving any more attention to its problems. Bateson was still cautious, pointing out several weighty difficulties of the theory, and did not consecrate himself to its investigation.

Edmund Wilson was one of the key actors in the first act of the chromosome theory of inheritance. Sutton's work was developed in his laboratory, and it was Wilson who publicised this research and associated it to Boveri's results, proposing the name "Sutton-Bovery chromosome hypothesis." He also played a main role in the establishment of a relation between sex and chromosomes. Besides his personal contributions, he trained and influenced some young researchers, namely Alfred H. Sturtevant, Calvin B. Bridges, and Hermann J. Muller who brought contributions to the Mendelian chromosome theory of inheritance.

Given Wilson's early role in the development of this theory, one could expect that he had a strong belief in the theory itself and in its fundamental hypothesis from the very beginning. It is surprising, therefore, to find some sceptical comments published by Wilson during this stage, such as this one:

... But I hardly need had that this should not be considered as giving more than a tentative point of attack. It is entirely possible that we are on a wrong track, that the so-called sex chromosomes are only associated in a definite way with the sexual characters, and have in themselves no causative influence on sex production. The whole chromosome theory of heredity, for that matter, stands unproven before the judgment seat. I repeat, therefore, that the subject is not yet ripe for discussion; and what we need now is not more theory or discussion, but more observation and experiment. I believe that the chromosome theory as applied to the sex problem presents a sufficiently plausible face to be taken for a time as a guide 
to further examination of the facts. Perchance the true explanation may be found on the way; even should our working hypothesis prove a false leader. (Wilson 1907, 378-9)

As it will be shown in this paper, the above citation was not an isolated event-it was typical of Wilson's attitude. Here we can find a researcher who has serious doubts concerning the chromosome theory of inheritance and the causal association between chromosomes and sex, but who nevertheless dedicates most of his time to the research of those issues. Wilson's standpoint is clearly different from those adopted by Bateson and Morgan, and it is not a very usual one. The aim of this paper is to analyse and elucidate Wilson's attitude, especially in the two first decades of the 20th century.

\section{The Situation in the First Decade of the 20th Century}

The main scientific contributions of Edmund Beecher Wilson (1856-1939), up to 1900, were in the field of embryology (Muller 1943, 8-13). At first, he had no specific interest in heredity or cytology. However, in the 1890's, he dedicated himself to cytology and published two editions of his famous treatise The Cell in Development and Inheritance (1896; 1900). This book contained a detailed discussion about the relation between the cell nucleus and heredity—a subject that was widely discussed at the time. Wilson was favourable to the conclusion that the nucleus contained the physical basis of heredity and that its chromatin (which he identified with the idioplasm postulated by Nägeli's theory) was the carrier of the hereditary characters (Muller 1943, 32-34).

At that time, it was not known whether the chromosomes were permanent bodies or were produced only during the cell division - the only occasion when they were clearly seen. Wilson was well acquainted with the observational difficulties, but he seemed to believe in the individuality of chromosomes mainly grounded in the evidence found by his friend Theodor Boveri in Ascaris (Wilson 1900, 294-304; Martins 1997, chapter 3, 26). He also favoured some of Weismann's ideas and accepted that during meiosis there occurred a reduction of chromatin. It seemed, at that time, that the chromosomes were united by their extremities, and that the reduction division would be a transversal one (Muller 1943, 35-36). The details of meiosis had not been cleared up.

In 1902, Walter Sutton, who was working with Wilson at the Columbia University, published a paper dealing with the spermatogenesis of a grasshopper, Brachystola magna. He suggested that the association of the paternal and maternal chromosomes and their subsequent separation during cell division could constitute the physical basis of the Mendelian law of heredity (Sutton 1902, 39). In the same year, William A. Cannon-a botanist who was also working at the Columbia University-published a paper in which he studied the formation of pollen in a cotton hybrid and examined the possibility of a cytological basis for the Mendel's law of the splitting of the hybrid race (Cannon 1902). In this study, he assumed that there was no intermixture of paternal and maternal chromosomes - each gamete would have either one set of chromosomes or the other one (Martins 1999b, 266-7). In December, Wilson wrote a short note that was published in Science announcing the ideas of the two students of his University concerning a cytological interpretation of Mendel's principles of inheritance (Wilson 1902). It is likely that besides intending to make known the ideas of those students, he also intended to take partial credit for the proposal (Martins 1999b, 267).

According to Wilson, Sutton had concluded that the behaviour of chromosomes during union and division "probably gives the explanation of the Mendelian principle.” Wilson linked Sutton's work to Boveri's result concerning sea-urchins, that "strongly suggests, if they do not prove, that the individual chromosomes stand in definite relation to transmissible characters taken singly or in groups” (Wilson 1902, 992). Even admitting that 
cytological evidence was still incomplete and that he was dealing with a conjecture (Wilson 1902, 992), he thought that Sutton's cytological studies on the Brachystola magna provided strong evidence for that conclusion.

In this paper, Wilson still interpreted meiosis in the old Weissmanian sense. Besides that, it seems that he believed that in synapsis the paternal and maternal chromosomes were united by their extremities. Moreover, he also believed that the paternal and maternal chromosomes were inseparable groups (Martins 1999b, 267-8).

All over his article, Wilson was careful enough to state that there was no clear-cut proof of the hypothetical relation between chromosomes and Mendel's factors. And he concluded the paper with those careful but encouraging words: "Should the study of the maturation-divisions indeed reveal the basis of the Mendelian principle that we shall have another and most striking example of the intimate connection between the study of cytology and the experimental study of evolution” (Wilson 1902, 993).

In the same year, Clarence E. McClung (1870-1946) published the first clear suggestion that sex was related to specific chromosomes. He noticed that there was a single (unpaired) chromosome in the males of some insects (McClung 1901). Half the spermatozoa produced by the insect carried this "accessory chromosome," and the other half lacked it. McClung assumed that the ovules fertilised by spermatozoa containing the accessory chromosome would produce males, and the others would produce females (McClung 1902). This was "McClung's hypothesis" concerning sex determination. He had only examined male insects and had no information regarding the chromosomes of the females.

Although McClung's hypothesis was mistaken it triggered a series of researches, some of them had confirmed his results—such as Sutton's studies of Brachystola magna — and others had denied them—such as the studies of Thomas H. Montgomery in Hemiptera (Martins 1999a).

Starting from McClung hypothesis and other subsequent researches, Wilson and Nettie Maria Stevens (1861-1912) also investigated whether there was a relation between chromosomes and sex. They published a series of papers from 1905 to 1912, convincing several scientists (including William Bateson) that they had found a specific physical external characteristic that could be related to special chromosomes.

Both Wilson and Stevens devoted their time to the study of several genera of insects, including Hemiptera. They found different patterns of sex determination in several genera they examined. ${ }^{1}$ The situation was highly complex that, because the observations were seldom distinct, the interpretation was usually ambiguous; there were always exceptions and the theoretical explanation of the facts was controversial. The text-book version of this episode provides no hint to the intricacy of the situation during those early years.

The aim of this paper is not to present a detailed description of those researches, but to discuss Wilson's outlook concerning the chromosome theory of inheritance and sex. It will be seen that he maintained a coherent and peculiar perspective as regards those subjects and biological research generally.

\section{The Method of Analysis}

The method of analysis that will be applied to the present case was described elsewhere (Martins \& Martins 1999; Martins 2002). The attitude of a scientist towards a theory can be analysed taking into account three main components of his observable posture:

(1) The explicit opinion of the scientist as regards the truth/value of the theory (cognitive attitude);

(2) The views declared by the scientist concerning the importance of investigating or using the theory (instrumental attitude); and 
(3) The actual dedication of that scientist to the research or use of the theory (strategic attitude).

Let us begin by the third component - the strategic attitude. During the first years of the 19th century, Wilson published several papers on embryology—his old research subject. However, from 1905 to 1914, he published about 20 papers concerning chromosomes and their relation to sex and heredity. Doubtless, during this period, Wilson was strongly dedicated to the chromosome theory: He devoted most of his time to researches in this field.

This strong dedication is an indication that the scientist regards his practical commitment to the theory as useful to attain his goal—but the goal itself can be of different types. This attitude is usually (but not always) accompanied by a strong belief in the truth of the theory that guides the research. Of course, there are extreme cases in which a scientist devotes most of his effort to a theory because of external demands without believing in the theory itself. However, it seems that Wilson's behaviour was not the result of institutional pressures or group coercion. He was not following a fashionable line of research, either. What did Wilson have in mind? What did he expect to attain? The analysis of his cognitive and instrumental attitudes will help us to understand his behaviour.

\section{Wilson's Cognitive Attitude}

There are two extreme cognitive attitudes that a scientist can adopt as regards some conception. He may believe that a theory is correct and well grounded, maintaining no doubts about its truth. The opposite attitude is a belief that the theory is wrong and that there are solid arguments and/or evidences against it. Between those limits it is possible to find a continuum of opinions. Let us analyse Wilson's point of view.

In 1905, Wilson began the publication of a series of papers on chromosomes. In the first one, he described what he called the idiochromosome of several Hemiptera (Wilson 1905a). Following the suggestion that had been presented by McClung, Wilson attempted to find a relation between those special chromosomes and sex determination. However, the results were confusing and Wilson was unable to find any understandable pattern. "Whether these difficulties can be met by assumptions of dominance and the like remains to be seen; but the fact should be recognized that as far as the Hemiptera are concerned neither the suggestion I have made, nor the hypothesis of McClung has at present any direct support in observed fact” (Wilson 1905a, 403).

In his second paper, Wilson was not very optimistic, either:

How the foregoing conclusions and suggestions regarding the idiochromosomes and heterotropic chromosomes will square with McClungs's hypothesis and my own similar suggestion that these bodies may be in some way concerned with sex-determination, does not yet clearly appear from the known data... (Wilson 1905b, 538)

In 1906, Wilson presented more observations concerning the relation between sex and chromosomes. Although there were differences between several Hemiptera he studied, his conclusion was that in most species there were visible differences between the chromosomes of the males and females. In some cases, the males had one unpaired chromosome, in other cases the males had two different chromosomes, corresponding to a pair of equal chromosomes in the female. In the case of Nezara hilaris, however, all chromosomes seemed to be equal in both sexes (Wilson 1906, 20-22). He concluded: “At least a possibility is thus established that in organisms generally both eggs and spermatozoa may be predestined as male-producing and female-producing forms, whether they are visibly different or not” (Wilson 1906, 27). 
It was not clear, however, how sex could be produced by a chromosome difference. William E. Castle (1867-1962) had proposed a Mendelian explanation of sex, but Wilson remarked that this hypothesis required the acceptance of selective fertilization. He did not favor this explanation and proposed a quantitative interpretation, but he pointed out that there were experiments made by Lucien Cuénot that supported selective fertilization, and commented: "I therefore think that the possibility of a Mendelian interpretation of sex-production should be carefully examined, though as will be shown, an alternative interpretation is possible" (Wilson 1906, 27-28).

Several comments presented by Wilson, such as those, suggest that his cognitive attitude concerning the relation between sex and chromosomes was neither full acceptance nor scepticism, but an intermediary one. The hypothesis could be regarded as a viable alternative (not impossible), although there were just a few favourable facts, many exceptions, and the explanation of the observed regularities was not clear at all.

In a paper published in 1907, Wilson discussed sex determination in the case of parthenogenesis. From the very beginning of the paper, Wilson acknowledged that the situation was confused:

It is not an easy task to attempt a brief discussion of the relation of sex determination to fertilization and parthenogenesis; for the fact may as well be admitted at the start that we are not yet in a position to make any general statement as to what that relation is, and it is my impression that the subject is not yet ripe for discussion. (Wilson 1907, 376)

In several of his papers, such as the former one, Wilson implied that it is safer to postpone any verdict, for the time being. Even in the cases where he did choose one specific interpretation of the facts, he warned his readers that his opinion could readily change:

In making some inquiry into the causal relation between sex and the chromosomes, I wish not to appear as a special pleader for any particular theory. We still know too little of the physiological meaning of the chromosomes to commit ourselves unreservedly to any fixed theory or interpretation regarding the part they play in sex-production. My intention is only to analyze briefly the possibilities suggested by the facts. If certain of these possibilities are characterized as more probable than others, it is with entire readiness to accept a different view as soon as new facts may change the aspect of the problem. (Wilson 1909c, 584)

At some places, Wilson presents a more positive view of the relation between sex and chromosomes, but always accompanied by cautious remarks:

In one case only has it thus far been possible to demonstrate a constant relation between particular chromosomes and particular characters, namely in the case of sex and sex-limited characters. It is true that in this case we are not able to assert that the sex-chromosomes are the primary determining cause of sex-indeed, there seems to be good evidence to the contrary. Unless, however, we are prepared to defend the proposition that the sex-chromosomes are absolutely functionless we shall not, I think, escape the conclusion that they form one of the factors in sex-heredity. (Wilson 1912, 65)

\section{Wilson's General Views Concerning Theories}

Wilson's attitude concerning the chromosome theory is not an isolated case. His general attitude towards theory is usually the same- a cautious discussion of favourable and negative evidence and arguments, and a sceptic outlook concerning the possibility of solving the most important scientific questions.

In an address he gave in 1901 to the American Society of Naturalists, for instance, Wilson described the situation of the field in the following words: "the present period of intense activity in natural science, of rapid development of new aims and methods, and of continually shifting point of view" (Wilson, 1901, 14; my emphasis). He was well aware that no substantial agreement had been reached by naturalists concerning some 
of the most fundamental problems of the discipline, such as the origin of the main groups of living beings (Wilson 1901, 17) and that there were limits to scientific knowledge: "I do not doubt that the progress of research will in time bring us much nearer to a definite solution of these great problems; though it lies in the nature of the case, that we can never attain complete certainty" (Wilson 1901, 17).

Another example of the same attitude can be found in Wilson's remarks concerning his older research subject—embryology and development:

We have at present no positive data for an answer to these questions... What is the object of the study of development? I should state this object somewhat as follows: First, to observe and to describe as completely and simply as possible the actual phenomena of development; secondly, to determine to what extend, from its beginning in the egg to its completion in the adult organism, the process can be formulated in terms of the elementary laws of matter and of motion... Now, I do not need to say that even the approximate accomplishment of these aims is still very remote, their complete accomplishment impossible. (Wilson 1905c, 293; my emphasis)

In his 1914 Presidential Address to the American Association for the Advancement of Science, Wilson presented his views on the limitation of science in a very clear way:

We perceive more and more clearly that science does not deal with ultimate problems or with final solutions. In order to live, science must move. She attempts no more than to win successive points of vantage which may serve, one after another, as stepping stones to further progress. When these have played their part they are often left behind as the general advance proceeds. (Wilson 1915a, 2)

\subsection{Wilson's Views Concerning Facts and Theories}

Wilson's general scepticism (or, perhaps, agnosticism) concerning the scientific theories was counteracted, however, by his belief that science may reach positive results regarding facts which are accessible to more direct investigation. In the same address in which he expressed his doubts concerning the possibility of arriving at the solution of the main evolutionary problems, he remarked:

The relative decline of interest in genealogical questions is partly due, I think, to a healthy reaction against the inflated speculation into which morphologist have too often allowed themselves to fall; but it is also in large measure a result of the growing feeling that the solution of the broader problems of genealogy still lies so far beyond our reach that we would better turn for a time to the study of questions that lie nearer at hand and are, to say the least, of equal interest and importance. (Wilson 1901, 17; my emphasis)

In a paper published in 1906, where Wilson reviewed the Mendelian and the quantitative hypotheses of sex determination, pointing out their advantages and difficulties, he added this comment:

Additional data will therefore be required, I think, to show whether the difficulty in question is a fatal one, and in what measure either of the two general interpretations that have been considered may approach the truth. The positive result of the observations of Stevens and myself is to demonstrate the existence of a constant and definite correlation between the chromosomes and the sexual characters, which is visibly expressed in the relations of a single pair of chromosomes. These relations unquestionably afford a concrete basis for an interpretation of sex-production that assumes a Mendelian segregation and transmission of sex-characters and to this extent they accord with the general assumption of Castle. The validity of both this and the alternative interpretation suggested must be tested by further inquiry. (Wilson 1906, 38-39; my emphasis)

Some regularity had been found, and Wilson did not entertain serious doubts concerning those phenomena. The interpretation of those facts, however, was doubtful. Similar remarks appear over and over in his publications: 
We return from our excursion into the theoretical field compelled to admit that the data for an adequate or definitive general interpretation of sex are not yet at our command. Cytological research has nevertheless made a substantial advance towards the solution of the problem. The cytological phenomena that have been described have already led to a better understanding of sex-production; and the concrete results of observation must not be confused with any of the theoretical interpretations that we may place upon them. (Wilson 1909c, 592; my emphasis)

In some of his writings, Wilson did even condemn science to ignore facts and the laws of nature: "Nobody is able with perfect accuracy to observe, measure, or weigh anything. We are always in error, more or less" (Wilson 1915b, 627). "No particular law of nature-and here I employ the words of a great master of mathematical physics - will ever be more than approximate and probable, nor can we state it completely" (Wilson 1915b, 628). Although Wilson was aware of the overall limitations of science, in his practice he did assume that it was possible to reach definite results concerning facts (generalisations) but not theories.

\subsection{Wilson's Views Concerning the Use of Theories and Hypotheses}

What, then, is the use of theories that can never be proven? Should the scientist reject all theories and stick to facts? No, Wilson did not think so. He thought that hypotheses and theories were useful, except when this became a barrier to further research:

... Such is the ultimate question of ontogeny, which in one form or another has been debated by embryologists for more than two centuries. We still cannot answer it. If we attempt to do so, each replies according to the dictates of his individual temperament- that is to say, he resorts to some kind of symbolism; and he still remains free to choose that particular form which he finds most convenient, provided it does not stand in the way of practical efforts to advance our real knowledge through observation and experiment. (Wilson 1915a, 7)

Wilson regarded some theories and hypotheses as unproductive, while other was useful in guiding research and leading to the discovery of new facts. In his 1914 Presidential Address to the American Association for the Advancement of Science, Wilson compared vitalism to mechanism. He admitted that vitalism could be correct. He also acknowledged that the hypotheses of vitalism could "be of practical use in our investigations on living things, or find their justification on larger grounds of scientific expediency" (Wilson 1915a, 5-6). However, he considered that the vitalistic outlook could avert scientists from observation and experimentation, becoming in that case obstacles to the scientific development:

... the more we ponder the question, the stronger grows our conviction that the "entelechies" and such-like agencies conjured forth by modern vitalism are as sterile for science as the final causes of an earlier philosophy; so that Bacon might have said of the former, as he did of the latter, that they are like the Vestal virgins—-dedicated to God, and barren. (Wilson 1915a, 5)

In a similar way, the mechanistic outlook was not regarded by Wilson as true, but as a useful strategy:

We have, it is true, no proof whatever of its (the mechanistic method) final validity. We do not adopt the mechanistic view of organic nature as a dogma but only as a practical program of work, neither more nor less... We shall make lasting progress only by plodding along the old, hard beaten trail blazed by our scientific fathers-the way of observation, comparison, experiment, analysis, synthesis, prediction, verification. If this is a prosaic program, we may learn otherwise from great discoverers in every field of science who have demonstrated how free is the play that it gives to the constructive imagination and even to the faculty of artistic creation. (Wilson 1915a, 6)

It seems that Wilson feared barren speculation and recommended any strategy that could yield palpable results: "Every really rational naturalist must admit that there is but one sane position to adopt, namely, to 
welcome any and every method by which our knowledge of organic nature may be advanced and unified" (Wilson 1901, 21).

According to Wilson, the scientist is free to choose theories and hypotheses that stimulate empirical investigation and that should be submitted to the results of observation and experiment. In another paper published in the same year, Wilson developed the analogy between the researcher and the player:

The value of science... depends mainly upon the attitude of the scientific investigator towards the study of nature. For, he, too, is like a player in a great game. He is quite aware that he can never bring it to a conclusion or sound all of its depths. Nevertheless, he throws himself into it without hesitation, certain of its inexhaustible interest and of possibilities of achievement that are past all reckoning. (Wilson 1915b, 626)

The theories and hypotheses are not a result of the empirical investigation-they are produced by the "constructive imagination" of the scientist. However, the scientist should not be dominated by them. They are means useful in his research, but should be kept under control: "Science should develop-and it should discipline-the constructive imagination” (Wilson 1915b, 626). Theories and hypotheses are useful as instruments that may lead the researcher to the discovery of new facts.

Science should teach us to keep an open mind, to look facts straight in the face. It should help to deliver us from the deadly vice of thinking we know things of which we are really ignorant. It should lead us to place a higher valuation on observation and experiment than on authority and precedent. (Wilson 1915b, 626)

Not merely in a spirit of sportsmanship does science play her game; she also strives to realize an ideal, one that is very plain and simple. And this ideal is, in a single word, progress. Not to solve the ultimate riddles of the universe, if such there be, not to attain to absolute truth, but to advance knowledge—such is the aim of science. (Wilson 1915b, 628)

Wilson did not regard science as a search for deep truths, but as a playful activity.

Malebranche is nearer to it (the actual attitude of science) in that delightful remark that if he held truth captive in his hand, he would open his hand and let it fly, in order that he might pursue and capture it again. Here we sense the spirit of the sportsman. With somewhat of the same spirit, beyond a doubt, does the discoverer play his small part in the mighty game of science? (Wilson 1915b, 628)

This gives us a good idea of what Wilson thought about science, in general. However, it sometimes happens that the scientific practice of a scientist is not in harmony with his philosophical discourse. It is necessary, therefore, to analyse his scientific writings and check whether this attitude was indeed maintained in his research.

\section{Wilson's Instrumental Attitude}

As in the case of cognitive attitudes, there are also two extreme instrumental attitudes that a scientist can adopt respecting any conception. He may believe that a proposal is very useful as a working hypothesis and that it is worthwhile to study it, using it or submitting it to tests, because it is probable that it will produce valuable results. The opposite attitude is the belief that the said proposal has no value as a working hypothesis, and that it will be harmful or profitless to study it, to employ it or even to test it, because it is unlikely that it could lead to valuable results. Between those limits, it is possible to find a continuum of viewpoints. The instrumental attitude should be analysed taking into account the statements of the scientist regarding what is useful or harmful. The effective scientific practice of the scientist may agree or disagree with his statements, and corresponds to the third type of attitude (the strategic one), that was already analysed. 
Let us analyse Wilson's point of view concerning the chromosome theory. From the very beginning of his research on chromosomes and sex, it seems that Wilson did regard the chromosome hypothesis as just an instrument leading to possible discoveries:

The practical interest of the idiochromosomes lies in the very definite basis that they give for an examination of the question by the study of fertilization, for their disparity in size gives us the hope of determining their history by direct observation. There is a good reason to believe that such a study will yield interesting results. (Wilson 1905a, 403; my emphasis)

Hence, the conclusion becomes probable that there is a definite causal relation of some kind between the individual chromosomes and the development of corresponding characters or groups of characters; or, in other words, that the hereditary characters are in some manner distributed among the chromosomes which form their physical basis in the egg. We do not yet know in precisely what form this conclusion should be formulated. We do not know, for instance, whether a single unit-character, such as color, is determined by a single chromosome, or by a combination of chromosomes, or whether this may vary in different cases. In this direction, we have taken but the first uncertain steps towards a new horizon of discovery. (Wilson 1905c, 291; my emphasis)

When Wilson discussed the interpretation of the supposed relation between sex and specific chromosomes, he first presented William Castle's Mendelian interpretation, and then proposed his own hypothesis without claiming that it was closer to truth or more probable:

It has not been my intention to advocate the foregoing (Mendelian) interpretation, but only to set forth as clearly as possible, the assumptions that it involves. It is nevertheless my opinion that the analysis places no insuperable obstacles in its way, and that, however dominance be determined, the Mendelian interpretation may in fact give the true solution of the problem. I have, however, endeavored to seek for a different interpretation that may escape the necessity of assuming a selective fertilization; and although I have to offer nothing more than suggestions, some of which undoubtedly encounter serious difficulties, I shall make them in the hope that they may afford some clue to further inquiry. (Wilson 1906, 33; my emphasis)

Having noticed that in many insects there seemed to be a relation between sex and some specific chromosomes, Wilson turned to parthenogenesis as a possible way of obtaining additional evidence. If the difference between the sexes were produced in fertilization, by two different spermatozoa, then all ovules should be equal and it would be very difficult to understand how could parthenogenetic females produce both males and females.

The observed facts were very hard to explain by any single hypothesis. He suggested that Nettie Stevens' observations on aphids could perhaps be explained by considerations of "dominance of the female element" in summer, and that "males are produced from eggs in which a reversal of dominance takes place" (Wilson 1907, 378).

Whether similar considerations of dominance and recessiveness will afford a general explanation remains quite an open question, but they seem at least sufficiently plausible to be taken as a convenient working hypothesis. By its aid, we can work out on paper a formal explanation of the mechanism of sex production that will include nearly all known cases, and will also include the determination of sex by external conditions (if it be admitted that such a process takes place). It would not, I think, be profitable to go into such speculative constructions in detail here. They are but fireside dreams which may serve a useful purpose in the safe seclusion of the study, but really belong in the same limbo with the so-called "fool experiments" which all of us at times secretly practice. (Wilson 1907, 378; my emphasis)

One of the central assumptions of the chromosome theory of inheritance (and sex) was the individuality and constancy of the chromosomes. In a paper published in 1909, Wilson admitted that those assumptions were probably wrong, but nevertheless claimed that they should be used as working hypotheses: 
It may be admitted that many of the facts seem at present difficult to reconcile with the view that the identity of the chromosomes as actual individuals is maintained in the "resting” nucleus; and I have myself indicated (The Cell, 1900, 300) that the name "individuality" was perhaps not the best that could have been chosen. Certainly we have as yet comparatively little evidence that the chromosomes retain their boundaries in the "resting” nucleus. It is evident that the chromosomes are greatly diffused in the nuclear network, and it may be that the substances of different chromosomes are more or less intermingled at this time. Fick's "manoeuvre-hypothesis," which treats the chromosomes of the dividing cells as temporary "tactic formations," may therefore be in some respects a more correct formulation of the facts than that given by the hypothesis of "individuality" in the strict sense of the term. But the last word on this question has by no means yet been spoken. (Wilson 1909b, 194)

However this may be, in my view the most practicable, indeed the almost necessary, working attitude is to treat the chromosomes as if they were actually persistent individuals (Wilson 1909b, 197; emphasis of the author).

A last citation, from a later paper by Wilson, clearly shows his instrumental attitude towards the chromosome theory of inheritance:

I will not enter upon the analytical subtleties of the problem whether the chromosomes, or the substances that they contain, are permanent and self-propagating elements or are merely temporary products of an unseen underlying activity-whether they are causes, effects, or mere accompaniments of the specific reactions with which they are somehow connected. These are fundamental questions; and some of them cannot yet be answered. But we should not hesitate to adopt what seems likely to be for the time the most reasonable and fruitful working view. "Hypotheses," said Pasteur, "come into our laboratories by armfuls; they fill our registers with projected experiments, they stimulate us to research—and that is all.” In my view, studies in this field are at the present time most likely to be advanced by adopting the comparatively simple hypothesis that the nuclear substances are actual factors of reaction by virtue of their specific chemical properties; and I think that it has already helped us to gain a clearer view of some of the most puzzling problems of genetics. But even if we adopt the opposite view that the formation, segregation, and distribution of these substances are only signs or indices of what lies behind them, we still have in this direction one of the most promising paths of approach to a study of the activities of the germ-cells in heredity. (Wilson 1912a, 65)

It will perhaps be said that such conceptions of the nuclear organization as have here been indicated are both vague and artificial. Vague and crude they undoubtedly are; and so they will remain until we have far more thoroughly explored a field of inquiry in which we must for the present make a shift with crude ideas unless we are content to work with no ideas at all. (Wilson 1912, 65-66)

We may as well recognize the fact that our present rude notions of cell-organization have not yet progressed very far beyond the paleolithic stage of culture; but they are of use in so far as they help to open new points of view or to discover new facts, whether in cytologic or in genetic inquiry. It seems to me that in both regards they have already proved worthwhile. (Wilson 1912, 67)

It would be possible to cite many other statements by Wilson that point to the same direction: Even though he doubted the truth of the hypothesis under discussion, he presented it as a very useful working hypothesis that would probably produce valuable results. His attitude was strongly instrumental, in the sense mentioned above.

\section{Conclusion}

The attitude of Wilson regarding the chromosome theory seemed at first sight peculiar and difficult to understand. In the case of Thomas Morgan and William Bateson, their cognitive, instrumental, and strategic attitudes make an easily comprehensible system of beliefs and behaviour. Their set of attitudes is that of realist scientists, who devote themselves to the research of a theory because they believe it is true (or highly probable). 
In the case of Edmund Wilson, on the contrary, his practical commitment to the study of the chromosome theory seemed incompatible with his doubts concerning the truth of that theory.

The analysis presented in this paper showed that Wilson's strategic attitude was indeed a strong practical involvement with the chromosome theory of inheritance, since he devoted most of his time to researches in this field, between 1905 and 1914.

Wilson's cognitive attitude concerning the relation between sex and chromosomes was neither full acceptance nor scepticism, but an intermediary one. The hypothesis could be regarded as a viable alternative (not impossible), although there were just a few favourable facts, many exceptions, and the explanation of the observed regularities was not clear at all.

Of course, it is impossible to understand Wilson's strategic attitude taking into account only his cognitive attitude. A coherent picture emerges, however, when we take into account his instrumental attitude. His statements imply that Wilson regarded the chromosome theory as a very useful working hypothesis and that it was worthwhile to study it, using it or submitting it to tests, because it was likely that this would lead to valuable results.

Wilson's instrumental attitude explains his strategic attitude. Besides that, his instrumental attitude is seen to be compatible with his cognitive attitude, because of his general views on the nature of scientific theories and hypotheses. We may characterise the specific combination of attitudes exhibited by Wilson as typical of instrumentalist researchers, who can entertain strong doubts concerning the cognitive status of a theory or hypothesis, and in spite of that can regard it as a valuable working hypothesis.

\section{Notes}

1. A detailed description of some studies from Stevens concerning the gametogenesis of several orders of insects from 1907 to 1909 as well as Wilson's three first studies on chromosomes (published in 1905 and 1906) can be found in Brito, 2004, chapters 2 and 3.

\section{Works Cited}

Allen, Garland E. Thomas Hunt Morgan. The Man and His Science. Princeton: Princeton University Press, 1978.

Brito, Ana Paula P. O. M. Nettie Maria Stevens e suas Contribuições para a Teoria Cromossômica da Hereditariedade (Nettie Maria Stevens' Contributions to the Chromosome Theory of Heredity). Master Dissertation. São Paulo: Pontifícia Universidade Católica, 2004.

Cannon, William A. “A Cytological Basis for the Mendelian Laws.” Bulletin of the Torrey Botanical Club 29.12 (1902): 657-61.

Mayr, Ernst. The Growth of Biological Thought: Diversity, Evolution, and Inheritance. Cambridge: Harvard University Press, 1982.

McClung, Clarence E. “Notes on the Accessory Chromosome.” Anatomische Anzeiger 20 (1901): 220-6.

---. “The Accessory Chromosome-Sex Determinant?” Biological Bulletin 3 (1902): 43-84.

Martins, Lilian A.-C. P. A Teoria Cromossômica da Herança: Proposta, Fundamentação, Crítica e Aceitação (The Chromosome Theory of Inheritance: Proposal, Foundation, Criticism and Acceptation). Ph.D. thesis. Campinas: UNICAMP, 1997.

---. "McClung e a determinação do sexo: do equívoco ao acerto (McClung and Sex Determination: From Mistake to Achievement).” História, Ciência, Saúde-Manguinhos (History, Science, Health-Manguinhos) 6.2 (1999a): 235-56.

---. "Did Sutton and Boveri Propose the So-called Sutton-Boveri Chromosome Hypothesis?” Genetics and Molecular Biology 22.2 (1999b): 261-71. 
---. “Diferentes 'Estilos' ou 'Personalidades Científicas': um Estudo de Caso (Different 'Styles' or 'Scientific Personalities’: A Case Study).” Ed. Norma Horestein and Leticia Minhot. Epistemología e Historia de La Ciencia. Selección de Trabajos de las XII Jornadas (Epistemology and History of Science. Selection of Works of the XII Jornadas), Vol. 8. Córdoba: Universidad Nacional de Córdoba, 2002. 258-65.

Martins, Lilian Al-Chueyr Pereira and Roberto de Andrade Martins. “Acceptación o Rechazo de las Hipótesis o Teorías: un Nuevo Método de Análisis (Acceptation or Rejection of Hypothesis or Theories: A New Method of Analysis).” Ed. Eduardo Sota and Luis Urtubey. Epistemología e Historia de la Ciencia. Selección de Trabajos de las IX Jornadas, Vol. 5. Córdoba: Universidad Nacional de Córdoba, 1999. 273-80.

Muller, Hermann Joseph. “Edmund B. Wilson—An Appreciation.” American Naturalist 77 (1943): 5-37; 142-72.

Sutton, Walter S. “On the Morphology of the Chromosome Group in Brachystola magna.” Biological Bulletin 4 (1902): 24-39.

Wilson, Edmund Beecher. The Cell in Development and Inheritance. 2nd ed. New York: Macmillan, 1900.

---. “Aims and Methods of Study in Natural History.” Science 13.314 (1901): 14-23.

---. "Mendel’s Principles of Heredity and the Maturation of the Germ-Cells.” Science 16.416 (1902): 991-3.

---. "Studies on Chromosomes I. The Behaviour of the Idio-chromosomes in Hemiptera." Journal of Experimental Zoology 2 (1905a): 371-405.

---. "Studies on Chromosomes II. The Paired Microchromosomes, Idiochromosomes and Heterotropic Chromosomes in Hemiptera.” The Journal of Experimental Zoology 2 (1905b): 507-45.

---. “The Problem of Development.” Science 21.530 (1905c): 281-94.

---. "Studies on Chromosomes III. The Sexual Differences of the Chromosome Groups in Hemiptera with Some Considerations on Sex Determination and Inheritance of Sex.” The Journal of Experimental Zoology 3 (1906): 1-40.

---. "Sex Determination in Relation to Fertilization and Parthenogenesis.” Science 25.636 (1907): 376-9.

---. "Studies on Chromosomes IV. The 'Accessory' Chromosome in Syromastes and Pyrrochoris with a Comparative Review of the Types of Sexual Differences of the Chromosome Groups.” The Journal of Experimental Zoology 6 (1909a): 69-99.

---. "Studies on Chromosomes V. The Chromosomes of Metapodius. A Contribution to the Hypothesis of the Genetic Continuity of Chromosomes.” The Journal of Experimental Zoology 6 (1909b): 147-205.

---. "Recent Researches on the Determination and Inheritance of Sex.” Science 29.732 (1909c): 53-70.

---. "Some Aspects of Cytology in Relation to the Study of Genetics.” American Naturalist 46 (1912): 57-67.

---. “Some Aspects of Progress in Modern Zoology.” Science 41.1044 (1915a): 1-11.

---. “Science and Liberal Education.” Science 42.1088 (1915b): 625-30. 